\title{
The Need for Improved Integration between PLM and KM: A PLM Services Provider Point of View
}

\author{
Berit Folkard ${ }^{1}$, Yves Keraron ${ }^{2, *}$, Damien Mantoulan ${ }^{1}$, and Roger Dubois ${ }^{2}$ \\ ${ }^{1}$ CIMPA, New Filton House, Golf Course Lane, Bristol BS34 7QW, UK \\ \{berit. folkard, damien.mantoulan\}@airbus.com \\ ${ }^{2}$ CIMPA, 5 avenue Didier Daurat, 31700 Blagnac, France \\ roger.dubois@eads.net, yves.keraron@airbus.com
}

\begin{abstract}
With widespread use of digital tools in industry, an increasing amount of data and knowledge can be edited, shared and made accessible throughout the product lifecycle. As such, new technologies, that provide a formal framework for managing and organizing the intellectual assets of a business, can significantly influence the application of knowledge and the extent to which this knowledge will serve as a source of sustainable differentiation. Similarly, much suggests that the management of knowledge can positively influence and support the links between individual activities in the value stream, hence enabling the product-centered approach, which is fundamental to product lifecycle management (PLM). This paper draws on our experiences as a PLM and Knowledge Management (KM) supplier and highlights industry examples in aeronautics. It explores the potential application of a combined approach that utilizes digital support to encourage the effective use of KM throughout the product lifecycle.
\end{abstract}

Keywords: Product Lifecycle Management, Knowledge Management, Product Structures, Engineering Processes, Complex Engineering, Methods and Tools, Digital Mock-up.

\section{Introduction}

The issue we address is the following: Knowledge Management (KM) and Product Lifecycle Management (PLM) are two strategic approaches that are facing new challenges in complex products engineering. As a service provider in KM and in PLM related activities, we consider the latest challenges in these fields. We highlight that the coupling between these approaches needs to be improved, with both seen as strategic and impacted by the capabilities of new information and communication technology. We believe an improved coupling could bring even greater benefits to businesses in the future.

The organization of our paper is as follows: After reviewing the main features of the competitive and innovative background of complex products engineering, we describe some new industrial approaches, respectively in PLM (Chapter 3) and in KM (Chapter 4), founded in our field experiences mainly in aeronautics, space and defence.

\footnotetext{
* Corresponding author.
} 
In Chapter 5, we consider examples of increased integration between PLM and $\mathrm{KM}$ and outline the first phase of a CIMPA study to better understand the required levels of integration of KM practices within the PLM environment.

In chapter 6, before drawing our conclusions, we review works and findings that may bring a stronger theoretical foundation to our investigations for a better understanding of the interdependencies between KM and PLM.

\section{Industrial Context and Needs}

The complexity of current product development practices and increasingly sophisticated customer demands and needs, are driving the requirement for business strategies that create a product-centered environment.

Businesses are progressively expected to be able to design and manufacture high quality products, of increased complexity and variety at reduced costs, whilst maintaining their competitive position in the market place. Similarly, a need to address a wider range of customer needs in a more efficient and reliable way is itself contributing to the increasing number and variety of complex products. These products "often have complex designs which in turn results in formation of a complex development environment that is characterized by complex information structure and flow" [1].

The aerospace industry clearly exemplifies this complexity by the sheer volume of parts used in producing a single commercial aircraft - a 747-400 has 6 million parts, half of which are fasteners [source: www.boeing.com] - its development involves thousands of drawings, and a lengthy testing programme depends greatly on stringent capture, retrieval and re-use of data and knowledge. In addition, a complex product, such as a commercial aircraft, is more susceptible to engineering changes and increased "discrepancy between the as-designed, as-built, as-installed and asmaintained versions of the product" [1]. As such, a framework, which systematically preserves both data integrity and effectively enables capture, retrieval and re-use of knowledge, is both a significant challenge and a business necessity.

Failure to respond to external business drivers, such as a change in customer needs, which would leave businesses with outdated products or services, would likewise put a business at a disadvantage. This means businesses that create products with long development processes, such as commercial aircrafts, are facing increased pressure to reduce time-to-market to stay competitive and ensure their long term future. The importance of this was underlined by Airbus in 2006, with the launch of its internally led Develop-Faster activity, the goal of which was to re-engineer the entire Airbus development process. The three driving objectives focused on reducing the development lead-time from approximately 7.5 years to 6 years, achieving maturity at Entry-IntoService (EIS) or service readiness at first flight of the aircraft, and the ability to achieve production ramp-up.

Earlier supply chain engagement is, and was for Airbus, a key enabler in achieving these ambitious targets. Indeed, extensive theoretical research and well-documented practical application in Japanese businesses have shown that early and extensive supplier involvement results in faster development processes and more economically successful business relationships [2, 3]. 
As such, it seems, businesses increasingly need a collaborative environment with contextual sources of knowledge, which can support key business operations. Such an environment would allow for faster decision-making, through increased access to information, facilitate a concurrent engineering framework, thus reducing time-tomarket, and more effectively integrate suppliers in the product development process through greater dissemination of knowledge.

However, crucially, the knowledge propagating this environment needs to be accurate, appropriate and enable businesses to make the right decisions. Mechanisms that allow for improvement in efficiency and productivity in manufacturing businesses must ensure that information or knowledge overload does not impede on the gains made and sought. As such, controlling knowledge in terms of quantity and quality, as well as its evolution throughout the product lifecycle, has become a significant technological and strategic challenge. Thus, the effective management of knowledge becomes the critical constituent for businesses looking to ensure sustainable, strategic competitive advantages [4].

Challenges remain, however, in response to increasing globalisation of business interests, distribution networks and collaborative alliances. It is no longer sufficient to respond purely to the needs of the local market or manage business knowledge in isolation of the supply chain. Businesses must instead apply a consistent set of business solutions that support the creation, management, dissemination and re-use of product knowledge, across the extended enterprise, from idea generation to end of product life.

As the main PLM and KM services provider to Airbus, and working closely with the EADS group and other aerospace, defence, shipbuilding, transportation and hightech manufacturing industries, CIMPA has extensive experience within complex engineering environments faced with these challenges.

\section{PLM, a Strategic Approach Supported by New Technology}

Many definitions of PLM exist. For J. Stark [5], "PLM is the activity of managing a company's products all the way across their lifecycles in the most effective way". E. Subrahmanian [6] insists on PLM as "a strategic approach for creating and managing an organization's product-related intellectual capital from its conception to retirement." M. Garetti and S. Terzi [7] see PLM as "an integrated approach that, with information technology aid, realizes an integrated cooperative and collaborative information product management during all the lifecycle".

For CIMdata [8], "PLM is a strategic business approach that applies a consistent set of business solutions that support the collaborative creation, management, dissemination, and use of product definition information, supporting the extended enterprise (customers, design and supply partners, etc.), spanning from concept to end of life of a product or plant, integrating people, processes, business systems, and information". The business solutions applied in a PLM approach can thus be understood as the utilization of best practice processes, methods, templates, applications and technologies, designed to address business objectives or to solve specific business problems. 
The concept of PLM first appeared in the 1990s when designers were faced with increasing amounts of product data generated from mature CAD tools. These product data, therefore, needed to be managed effectively and consistently. CAD editors and software firms proposed Technical Data Management Systems (TDMS) in order to address this issue. The capabilities offered by such management tools and the sophistication of the authoring tools, such as CAD-CAM, increased the need for better, easier, faster and more secure access to product related information. The reliability of this data was also crucial for people involved in the entire lifecycle of the product. PLM answered this need by sharing knowledge about products, including the way (in terms of processes and methods) to design, configure, manufacture reproduce and support them.

As illustrated in Figure 1 below, the success of the PLM approach, as an enterprise strategic approach, depends on the ability of the business to find the best alignment of its intangible assets with its value chain processes in order to meet its strategic objectives. This means that the design, implementation and sustainability of a successful PLM approach requires the integration of people, tools, methods and processes.

This integration covers three dimensions: Businesses, disciplines and extended enterprise.



Fig. 1. PLM approach as an enterprise strategic approach (Adapted from Kaplan-Norton [9])

From ideation to recycling or dismantling, a number of different businesses are involved along the lifecycle of the product. Up until now, the succession of businesses involved has happened in a sequential way. In order to achieve this in the most efficient manner, all have to share common knowledge about the product information. Within a type of business such as design, several disciplines are involved (mechanical design, electrical design...). All these disciplines impact each other and are highly dependent on the same product information, which explains a critical need to collabo- 
rate and exchange information. This situation is particularly true in the context of an Extended Enterprise as it implies the collaboration between the Original Equipment Manufacturer (OEM) and its supply chain, partners and customers.

Nowadays, product information is recorded and displayed through a wide variety of PLM software tools. The compilation and unification of all this information is managed by one tool: the Digital Mock-Up (DMU). The DMU is a 3D computer simulation based on 3D digital models. It can represent parts or the totality of a product and answers a need for collaborative work. Until recently, the use of DMU had been limited by technological constraints due to the huge volume of information required for a DMU representing a whole complex product. However, the main blockers have now been solved and DMU is really starting to serve its purpose of integrator within the three dimensions mentioned above (see Figure 2 below).

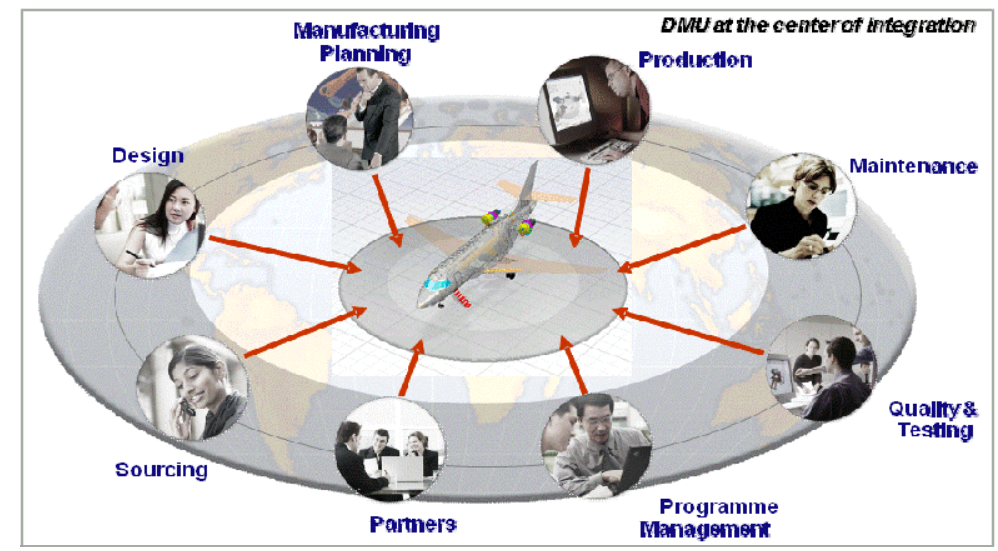

Fig. 2. DMU - A strong PLM paradigm at the centre of the integration

Most companies undertaking a PLM approach need to undergo profound cultural changes as the integration of people, processes, methods and tools required for such an approach can be very challenging. Without this integration, a PLM approach is very often reduced to a tool change project, far from meeting the expected benefits and strategic stakes. The complexity of this integration is increased by the high level of sophistication and maturity of the editor tools. As the tools become more sophisticated, users have to bridge an increasingly large gap in order to reach a level of knowledge that enables them to use the PLM tools to their full potential. As a result, companies are facing two challenges that are ever more difficult to overcome: the ability of the PLM tools to fit the user needs and the ability of the users to master the tools in an acceptable period of time. Specific know-how and methods need to be implemented in order to overcome these challenges. This requires the use of effective systems in order to acquire and disseminate new knowledge.

Thus the implementation of PLM methods and tools needs a strong focus on cultural change and therefore on increased management of a company's intangible assets. It is the reason why this paper highlights the need for the integration of KM and 
PLM approaches and for the systematic investigation of the impact of the new digital environment, symbolized by the DMU, on knowledge creation, knowledge hand-over and knowledge long-term retention.

\section{Knowledge as Critical to Business Competitiveness}

The knowledge base of any business has perhaps the greatest ability to serve as a source of sustainable differentiation in the market place. With increased complexity of development and production processes, businesses are forced to pay particular attention to the preservation and nurturing of knowledge assets [10], and how these can support PLM in the integration of all stages of the product lifecycle.

This section will briefly outline the concepts of tacit and explicit knowledge, as defined by the literature, and how these relate to each other in a business environment. We will explore how PLM and the wider ICT environment can support and facilitate the interplay of tacit and explicit knowledge throughout the product lifecycle by means of a codification or personalisation approach. We will then highlight the significance of KM in ensuring any such approach is in line with the strategic direction of the business.

\subsection{Concepts of Tacit and Explicit Knowledge}

According to Polanyi and Nonaka [11], knowledge can be largely defined as either tacit or explicit. Explicit or codified knowledge comes in the form of documents, books and databases, whereas tacit or un-codified knowledge is found in the experience of workers, embodies beliefs and values and is highly context dependent [11]. As such, tacit knowledge is difficult to articulate and document due to its observed and transitory nature. Yet, it can form the basis for the generation of new knowledge and as such is essential for the interpretation and understanding of existing explicit knowledge.

Knowledge Management (KM) governs four processes, each calling for particular treatment and consideration: knowledge creation, knowledge storage and retrieval, knowledge transfer and knowledge application [12]. The combination of all four processes has the potential to bring significant competitive advantages to a business.

Knowledge creation focuses on a continual interplay between the tacit and explicit dimensions of knowledge; how a spiral flow of knowledge moves through individual, group and organisational levels, and how knowledge is created via modes of socialisation (tacit to tacit), externalisation (tacit to explicit), combination (explicit to explicit) and internalisation (explicit to tacit), as depicted in Figure 3 below.

In the socialisation mode, tacit knowledge is shared between individuals without producing explicit knowledge. Collaboration and visualisation methods are typical components, which enable this exchange of ideas and experiences. In the externalisation phase, tacit knowledge is converted into explicit knowledge through conceptualisation and articulation. However, once knowledge has been made explicit, the combination mode enables the knowledge to be shared through various facilitation 
means, such as meetings, documentation and education programmes. Information and Communication Technologies (ICTs) are often used in the combination mode, to manage explicit knowledge and make its retrieval and transfer possible. Finally, in order to act upon and use the knowledge made explicit, individuals must first understand and internalise it. Through the internalisation mode, individuals can reexperience the explicit learning of others, thus creating new tacit knowledge.



Fig. 3. Tacit and explicit knowledge conversion (based on Nonaka's SECI model), adapted from [13, page 29]

The process of knowledge storage and retrieval, in turn, refers to ways in which stored knowledge is accessed and applied by individuals to influence business activities, and what retrieval mechanisms are available to them. Knowledge transfer is the process through which individuals, groups or departments are affected by and learn from the experience of others [14, 15]. Finally, knowledge application is concerned with the integration and application of knowledge in the business as a source of competitive advantage [12]. To make best use of this advantage, effective management of the knowledge made available is crucial.

\subsection{PLM as KM Enabler}

The IT infrastructure of PLM, and indeed the wider concept of ICTs, is readily accredited with the ability to speed up knowledge intensive work [16]. While virtual meeting applications and collaboration suites will facilitate the sharing of tacit knowledge, computer simulations, based on 3D models, are able to support knowledge externalisation by encapsulating types of design knowledge. In addition, document management systems can facilitate the mode of internalisation by making explicit knowledge more organised and available to the end user.

As such, PLM supports the KM processes highlighted above by enabling the creation of new knowledge, supporting individual and business learning, improving knowledge access and making available more channels of communication throughout the product lifecycle. As Ameri and Dutta reason, technology can thus not only successfully contribute to the creation of explicit knowledge, but also serve as a 'catalyst' for the creation of tacit knowledge, as it "can permit individuals to access required 
pieces of information in the right context" [1]. This is perhaps best exemplified by the complex design environment, which governs aeronautics, space and defence, and where the very characteristics of the PLM environment allows businesses to respond to ever greater challenges and market demands. In this environment, designers can consult, build upon and re-use solutions held by computer-aided technologies in order to arrive at the best possible design and manufacturing solution for the business. Thus, environments like the DMU, supported by continuous technological advances, encourage new ways of thinking for engineers and offer extended access to knowledge, made possible only through technology.

Within an engineering context, Bermell-Garcia et al distinguish between ICTs used to support a personalisation strategy, i.e. communication and team support through computer-supported collaborative work (CSCW) or codification strategy, such as information management, collaborative knowledge creation editors (such as WIKI) and knowledge-based engineering (KBE) systems [16].

As such, PLM offers the promise of both connecting individuals in ways that support human resources, collaborative working and communication, whilst providing a formal framework for managing and organising the intellectual assets of a business [1]. Indeed, such personalisation and codification approaches, according to McMahon et al. [18] are necessary in any design business and should not be mutually exclusive. However, it is crucial to align any emphasis and choice of tools - to support such approaches - to the business context, internal and external environment and culture. First and foremost, businesses must ensure that their business solutions and acquired skills and knowledge remain aligned to the corporate strategy. In other words, PLM, if implemented simply as a powerful suite of tools, may not reach its full potential, namely that of supporting lifecycle processes and enabling knowledge creation, sharing and re-use.

In our experience as a PLM and KM services provider, this strategic alignment is fundamental to business success. It is best achieved through an initial comprehensive diagnostic assessment, aimed at ensuring any KM solution implemented is both sustainable and supports the strategic direction of the business.

The business or business units must first identify and prioritise its most critical areas in terms of distinctive capabilities, as well as current and future knowledge needs. Critical knowledge areas should encompass key business processes, products, tools and technologies, but crucially also a people element. This is vital in order to ensure that any implemented knowledge management practices take into account, either implicitly or explicitly, the social context in which knowledge is created, shared and applied. Such a diagnosis will re-focus existing or new KM practices.

\subsection{KM as PLM Enabler}

Ultimately, the diagnostic assessment ensures that a coherent suite of services is implemented to be fully in line with the strategic direction of the business and the challenges it faces. It will then successfully complement and support existing processes, methods and tools within the PLM framework. Beylier et al shares this notion of involving engineers in the direction of the business's KM practices by ensuring tools 
and methods are integrated and support daily activities. He emphasises how KM services "must fit in with engineering practices" [17], thus providing a supporting environment for managing knowledge-intensive work.

As such, the implementation of KM practices should go beyond the support of individual tools, methods and processes when operating in a collaborative knowledge environment, as these may fall short in addressing the challenges faced by businesses. Instead, the real value of KM comes from ensuring alignment to the corporate strategy and effectively supporting the links between individual activities in the value stream, hence supporting the product-centered approach, which is fundamental to PLM.

From experience gained through working with large design and manufacturing businesses, KM practice implementation in line with a corporate strategy can take many forms. It may involve supporting competence and skills management drives for the overall business, through structured and facilitated person-to-person knowledge capture and transfer, or by facilitating tacit knowledge exchanges between engineers to aid the delivery of critical design solutions. Both are not primarily linked to business enabling processes, methods or tools, which ensure business continuity, but rather they enable the flow of knowledge, which binds the links in the value stream, thus ensuring businesses can meet the increasingly demanding needs of the industrial environment.

\section{Towards Systematic Integration of PLM and KM}

As highlighted above, PLM addresses many of the challenges faced by today's knowledge-intensive businesses, namely the need for a computational framework which seamlessly and effectively enables the capture, retrieval and sharing of product knowledge. It also allows for better integration of product stakeholders in the extended enterprise, thus providing a basis for knowledge accumulation and the sharing of intellectual assets.

Nevertheless, the very nature of PLM as a business solution, based largely on the integration of IT systems and their associated product models, still has limitations. In part, this is linked to the fact that PLM and the components that support it are still maturing [10, 19]. On the other hand, Gopsill and al. [20] highlight the impact of new technologies on PLM, enabling Knowledge Discovery by integration of data from more and more sources. The authors believe that these trends will enable the implementation of new business models like Product Services Systems with a better inclusion of Corporate Social responsibilities.

There is another aspect that deserves consideration; the concept of technology as an inherently 'black box'. To the individual design engineer, tools within the PLM framework may appear as methods, algorithms or technologies, which do not offer an explanation of how they work, yet allow for observable inputs and different emerging outputs. This not only adds significant uncertainty to the accuracy of knowledge associated with the PLM system, as for instance design solutions may be represented without an adequate rationale or 'decision tree', but also does not allow for knowledge and understanding of the tools themselves to develop. 
It is in this context, that KM can be a valuable and powerful enabler of PLM. Strategically aligned knowledge transfer and capture activities, which rely on the notion that knowledge is socially constructed and based on experience, can support the contextualisation of largely explicit knowledge embedded in these solutions. In addition, by allowing tailored KM activities to address complexities of codification, motivational constraints linked to knowledge sharing, trust and cultural change, it may be possible to overcome cognitive and social limitations of ICTs.

However, it is clear that specific business requirements for systematic integration of KM and PLM need to be better understood and developed further. This will provide much needed direction for PLM and KM practitioners to capitalise on the opportunities highlighted above and add significant value to ongoing activities in both fields. Certainly, there is much to suggest that some level of integration is increasingly being pursued in businesses in efforts to meet some of the challenges highlighted in Table 1 below.

For example, between 2005 and 2008, Airbus undertook a comprehensive Knowledge Management driven project to ensure design and engineering knowledge on legacy aircraft programmes was maintained until the year 2050, thereby enabling the company to deliver an excellent standard of long-term support to their customers despite potential obsolescence of tools and materials. The solution included a knowledge retention portal designed to provide future engineers with an entry point to required legacy information that would ultimately aid future decision making. As such, the solution both aimed to make tacit knowledge explicit and also to contextualise explicit knowledge.

Similarly, knowledge capitalisation practices have been used in Airbus to address limitations of computer simulation of 3D models. In one instance, missing or misrepresented data within the DMU prompted late changes and increased workload, as engineers unfamiliar with the design were not able to sufficiently interrogate the technical environment or appreciate the contextual gaps.

However, PLM equally has the potential to benefit the evolution of KM through new knowledge structures and computational capabilities. Indeed, we suggest, that the PLM environment (and particularly the DMU) should be studied in light of the increasing collaborative working it facilitates, aspects of synchronisation and simulation, and how it has the potential to add significant value to the cognitive processes of the engineers.

As such, Tables 1 and 2 below show the first phase of a comprehensive study by CIMPA to better understand the required levels of integration of KM practices within the PLM environment. 
Table 1. KM as PLM enabler

\begin{tabular}{|c|c|c|c|}
\hline KM as PLM enabler: & $\begin{array}{l}\text { Supporting tool use throughout } \\
\text { the value stream [1] }\end{array}$ & $\begin{array}{l}\text { Supporting process } \\
\text { visualisation [2] }\end{array}$ & $\begin{array}{l}\text { Supporting linkages between } \\
\text { process steps [3] }\end{array}$ \\
\hline PLM scenario & $\begin{array}{l}\text { Users are increasingly faced with } \\
\text { complex and multi-functional tools, which } \\
\text { exhibitvastprocessing power. }\end{array}$ & $\begin{array}{l}\text { In efforts to accelerate processes, ICTs } \\
\text { increasingly screen process steps and } \\
\text { hide the rationale, which users need for } \\
\text { decision making. }\end{array}$ & $\begin{array}{l}\text { Tools are to a large extent process-linked } \\
\text { and the successfulintegration of the } \\
\text { toolsets increasingly relies on data and } \\
\text { knowledge transferbetween the links. }\end{array}$ \\
\hline Primary aim of KM & $\begin{array}{l}\text { Articulation and conceptualisation of tacit } \\
\text { knowledge and know-how. }\end{array}$ & $\begin{array}{l}\text { Contextualisation of explicitknowledge } \\
\text { embedded in technological solutions (or, } \\
\text { addressing 'technology as a blackbox'). }\end{array}$ & $\begin{array}{l}\text { Increase exchange of tacitand explicit } \\
\text { boundary knowledge. }\end{array}$ \\
\hline $\begin{array}{l}\text { Primaryactivity with } \\
\text { respect to knowledge }\end{array}$ & $\begin{array}{l}\text { Knowledge transferand organisational } \\
\text { learning } \\
\text { Learning is acquired through a process of } \\
\text { knowledge externalisation, where tacit } \\
\text { knowledge is converted to explicitthrough } \\
\text { articulation amongst groups and } \\
\text { individuals. }\end{array}$ & $\begin{array}{l}\text { Knowledge capture and re-use } \\
\text { Knowledge is captured through a process } \\
\text { of socialisation and externalisation, where } \\
\text { tacitcontextual knowledge is exchanged } \\
\text { and subsequently converted to explicit } \\
\text { form. }\end{array}$ & $\begin{array}{l}\text { Knowledge creation and application } \\
\text { Knowledge is created and applied } \\
\text { through the development of } \\
\text { (professional) communities, where } \\
\text { experience, interestand ideas can be } \\
\text { shared and contribute to the community's } \\
\text { (and organisation's) collected knowledge } \\
\text { resources. }\end{array}$ \\
\hline $\begin{array}{l}\text { Primary perceived benefit } \\
\text { to the business }\end{array}$ & $\begin{array}{l}\text { Improved dissemination of expertise e.g. } \\
\text { from experts to novices, reduced learning } \\
\text { curves, and maintenance of a healthy } \\
\text { knowledge base through knowledge } \\
\text { exchange. }\end{array}$ & $\begin{array}{l}\text { Improved re-use of explicit knowledge } \\
\text { and capture of critical organisational } \\
\text { memory/ experience. }\end{array}$ & $\begin{array}{l}\text { Improved integration of knowledge } \\
\text { created by specialised knowledge } \\
\text { domains (e.g. design and manufacturing) } \\
\text { and/or supply chain integration. }\end{array}$ \\
\hline Critical success factors & $\begin{array}{l}\text { Trust and motivation to share / handover } \\
\text { and acceptknowledge; providing an } \\
\text { environment thataddress cognitive } \\
\text { limitations. }\end{array}$ & $\begin{array}{l}\text { Trust and motivation to share knowledge } \\
\text { and contribute to knowledge capture and } \\
\text { re-use. }\end{array}$ & $\begin{array}{l}\text { Organisational structures and } \\
\text { collaborative contexts that supporta } \\
\text { culture of sharing, accessibility and } \\
\text { knowledge creation. }\end{array}$ \\
\hline $\begin{array}{l}\text { Possible CIMPA KM } \\
\text { solution to integrate in PLM } \\
\text { solution(s) }\end{array}$ & $\begin{array}{l}\text { Knowledge Transfer, Communities of } \\
\text { Practice }\end{array}$ & $\begin{array}{l}\text { Knowledge Capitalisation (including } \\
\text { knowledge re-use). }\end{array}$ & $\begin{array}{l}\text { Communities of Practice, Knowledge } \\
\text { capitalisation and transfer. }\end{array}$ \\
\hline
\end{tabular}

Table 2. PLM as KM enabler

\begin{tabular}{|c|c|c|c|}
\hline PLM as KM enabler: & $\begin{array}{l}\text { Supporting the creation of new } \\
\text { knowledge [1] }\end{array}$ & $\begin{array}{l}\text { Supporting knowledge access } \\
\text { [2] }\end{array}$ & $\begin{array}{l}\text { Supporting the dissemination } \\
\text { of knowledge [3] }\end{array}$ \\
\hline KM scenario & $\begin{array}{l}\text { Enablingthe integration ofdata from } \\
\text { different sources, PLM supports the } \\
\text { stakeholderin the interaction and in the } \\
\text { synthesis of information and thus enables } \\
\text { the creation of knowledge. }\end{array}$ & $\begin{array}{l}\text { Productstuctures, Productviews, } \\
\text { Productvisualization to enable the } \\
\text { retrieve andappropriation of information } \\
\text { by the stakeholders }\end{array}$ & $\begin{array}{l}\text { Bring the best guarantees of the correct } \\
\text { interpretation of the information by all he } \\
\text { stakeholders of the extended enterprise. } \\
\text { Secure long-term knewledge retention }\end{array}$ \\
\hline $\begin{array}{l}\text { Primary aim of PLM } \\
\text { onvronment }\end{array}$ & $\begin{array}{l}\text { Tomake available multi-disciplinary } \\
\text { information sources }\end{array}$ & $\begin{array}{l}\text { To make available productrelated } \\
\text { Information } \mathrm{h} \text { forms relevant to the } \\
\text { knowledge recpient/user }\end{array}$ & $\begin{array}{l}\text { Links of the product data with reference } \\
\text { data libraries }\end{array}$ \\
\hline $\begin{array}{l}\text { Primary activity with respect } \\
\text { to knowledge }\end{array}$ & $\begin{array}{l}\text { Knowledge discovery and creation } \\
\text { PLlit toosetbringing together clata from } \\
\text { different sources and of different } \\
\text { stakeholders supports the } \\
\text { synchronisation of disciplines and the } \\
\text { emergence of new concepts }\end{array}$ & $\begin{array}{l}\text { Knowbdge acciuistion and re-use } \\
\text { Tacitknowiledge is developed through } \\
\text { internalisation of explick knowledge }\end{array}$ & $\begin{array}{l}\text { Knowledge hand-overand long-tem } \\
\text { rentention. } \\
\text { Explicitlenowledgere-use is contolled } \\
\text { and its combination is supported }\end{array}$ \\
\hline $\begin{array}{l}\text { Primary perceived beneft to } \\
\text { the business }\end{array}$ & $\begin{array}{l}\text { mproyed coordination of the } \\
\text { stakeholders. Innovation precess } \\
\text { support }\end{array}$ & $\begin{array}{l}\text { Improved decision-making enabledy } \\
\text { increased interrogative capabilitiss of the } \\
\text { tochnological environment }\end{array}$ & $\begin{array}{l}\text { Reduce all costs due to lack of } \\
\text { interoperability }\end{array}$ \\
\hline Criticalresources & $\begin{array}{l}\text { Skiled designers open to conversation } \\
\text { with other disciplines } \\
\text { Negotiation skils }\end{array}$ & DocumentManagement Skills & $\begin{array}{l}\text { Businessobjectand process Modelers } \\
\text { Information Architects }\end{array}$ \\
\hline Criticalsuccessfactors & $\begin{array}{l}\text { Trade-offbetwen the authority of mone- } \\
\text { discipline knowledge and the importance } \\
\text { of multi-disciplines interaction for } \\
\text { knowledge creation }\end{array}$ & $\begin{array}{l}\text { Technology enabingvisibity of the } \\
\text { product lifecycle from planning' } \\
\text { conception to retirement. Access to } \\
\text { knowledge repostories during operational } \\
\text { tasks }\end{array}$ & $\begin{array}{l}\text { Interoperability standards (ISO } 15926 . \\
\text { PLCS,OAIS ...) }\end{array}$ \\
\hline PLM solution & DMU Services & $\begin{array}{l}\text { Documentmanagement functions } \\
\text { integrated with PLM systems }\end{array}$ & Ontology enabled PLM systems \\
\hline
\end{tabular}


In order to develop this understanding, we aim first to test the validity of our assumptions relating to identified streams of KM and PLM enablement (represented in Tables 1 and 2; shown as streams 1, 2 and 3). An interview guide of different discipline's representatives, developed jointly with the customer business, will help show the extent of desired integration, relevance and limitations that we face. However, in particular, it should also highlight the opportunities for business advancements that a more seamless and systematic integration of KM and PLM could ultimately bring.

\section{Theoretical Background to Knowledge Structures and the Need to Systematically Investigate the Impact of Digital Means}

Anthropologists like Goody have highlighted the importance of the technical communication means on the ways of thinking of a given culture [21], [22], whilst Bachimont [23] has questioned the new types of knowledge structures developed with the technology of computers. Table 3 below gives possible correspondences between what the cited authors call the 'written culture' and the 'computational culture'.

Table 3. Graphical and computational knowledge structures (translated by the authors from [23], p. 75)

\begin{tabular}{|c|c|}
\hline Graphical knowledge structures & Computational knowledge structures \\
\hline List & Program \\
\hline Table & Network \\
\hline Formula & Layer \\
\hline Schema & Digital Mock-Up \\
\hline
\end{tabular}

The scope of this paper does not expand the works of Goody and Bachimont readers will find deeper analysis in the cited references. Our experience in assessing the impact of digital influences on knowledge structures [24], [25] has highlighted the benefits of these digital means and also their limitations - particularly in supporting the interaction of operation and maintenance workers through digital documents in aeronautics and the oil and gas industries. These findings should be carried forward to focus on the use of DMU from the first steps of the product lifecycle, taking into account its practical importance in terms of integration but also to explore the benefits and limitations of this approach - for example, in terms of knowledge appropriation and long term retention.

According to Bachimont [23], the DMU is the corresponding structure in the digital background to the schema/drawing in the graphical background. The DMU displays concepts visibly - building-up the product at a given point as the schema does. Moreover, the DMU allows computational visualization of changes to a product and its behavior over time, supporting thus the designers' activities and their synchronization. By extending the representation to $3 \mathrm{D}$, DMU enables the analysis of possible clashes during the design process and the synchronization of interdisciplinary works. 
The DMU adds also a possible temporal dimension to the spatial support of the schema or drawing which supports the current way of thinking of the designers. The DMU, thus, enables the control of spatial and temporal dependencies.

These findings mean that the knowledge structures emphasized by computer technology are not only the means to store, retrieve, and share existing knowledge but that these means will influence our ways for creating new knowledge in the future. As such, DMU as a new knowledge structure, conditioned by digital techniques, is critical for the ways of working and designing in industry.

These impacts should be further investigated. The industrial sector, where substantial use of digital tools is made in the quest for increased performance, provides a fruitful field to investigate the impact of these new tools on the ways of working and thinking. Such investigations bring improved methods and tools for the successful implementation or change of PLM toolsets. The example of the use of DMU should likewise be carefully studied in order to have better control of the efficient implementation and deployment of PLM systems.

By considering PLM as providing new means of creating knowledge in the new industrial context, it will on one hand make KM closer to the business processes and, on the other, offer improved guarantees of success in the implementation and deployment of PLM in the extended enterprise for the design, manufacture and support of complex products.

\section{$7 \quad$ Perspectives and Conclusion}

PLM is needed to address today's challenges of complex systems engineering. PLM brings major cultural changes, even in our understanding of knowledge, and in the relationships between industrial partners. Great effort is required to understand the impact of these changes and to implement sustainable PLM systems. As discussed, Knowledge Management, with a vision of distributed knowledge between PLM teams and tools, is a critical part of this approach and integral to its success.

\section{References}

1. Ameri, F., Dutta, D.: Product Lifecycle Management: Closing the Knowledge Loops. Computer-Aided Design \& Applications 2(5), 577-590 (2005)

2. Morgan, J., Liker, J.K.: The Toyota Product Development System: Integrating people, process and technology. Productivity Press, New York (2006)

3. Petersen, K.J., Handfield, R.B., Ragatz, G.L.: A Model of Supplier Integration into New Product Development. The Journal of Product Innovation Management 20, 284-299 (2003)

4. Jasimudin, S.M.: A Holistic View of Knowledge Management Strategy. Journal of Knowledge Management 12(2), 57-66 (2008)

5. Stark, J.: Product Lifecycle Management: 21 st Century Paradigm for Product Realization. Springer, London (2005)

6. Subrahmanian, E., et al.: The role of standards in Product Lifecycle Management Support. NISTIR 7289. NIST (2006) 
7. Garetti, M., Terzi, S.: Product Lifecycle Management: Definition, trends and open issues. In: Proceedings at the 3rd International Conference on Advances in Production Engineering, Warshaw, Poland, June 17-19 (2004)

8. CIMdata, Product Lifecycle Management - Empowering the Future of Business (2002), http: / / www. cimdata.com

9. Kaplan, R.D., Norton, D.P.: The Balanced Scorecard - Measures that Drive Performance. Harvard Business Review (February 1992)

10. Ackerman, M. (ed.): Sharing Expertise - Beyond Knowledge Management. The MIT Press, Cambridge (2003)

11. O'Dell, C., Grayson, C.J.: If Only We Knew What We Know. The Free Press, New York (1998)

12. Alavi, M., Leidner, D.E.: Review: Knowledge Management and Knowledge Management Systems: Conceptual Foundations and Research Issues. MIS Quarterly 25(1), 107-136 (2001)

13. Little, S., Ray, T.: Managing Knowledge: An Essential Reader. Sage Publications, London (2005)

14. Argote, L., Ingram, P.: Knowledge Transfer: A Basis for Competitive Advantage in Firms. Organizational Behavior and Human Decision Processes 82(1), 150-169 (2000)

15. Kalling, T.: Organization-internal Transfer of Knowledge and the Role of Motiva-tion: A qualitative case study. Knowledge and Process Management 10(2), 115-126 (2003)

16. Bermell-Garcia, P., Fan, I.-S.: Practitioner requirements for integrated Knowledge Based Engineering in PLM. International Journal of Product Lifecycle Management 3(1), 3-20 (2008)

17. Beylier, C., Pourroy, F., Villeneuve, F., Mille, A.: A collaboration-centred approach to manage engineering knowledge: a case study of an engineering SME. Journal of Engineering Design 20(6), 523-542 (2009)

18. McMahon, C., Lowe, A., Culley, S.: Knowledge management in engineering design: personalization and codification. Journal of Engineering Design 15(4), 307-325 (2004)

19. Newell, S., Robertson, M., Scarbrough, H., Swan, J.: Managing Knowledge Work. Palgrave, New York (2002)

20. Gopsill, J.A., McAlpine, H.C., Hicks, B.J.: Trends in Technology and their Possible Implications on PLM: Looking Towards 2020. In: International Conference on Product Lifecycle Management, Eindhoven, Netherlands (2011)

21. Goody, J.: The domestication of the savage mind. Cambridge University Press (1977)

22. Goody, J.: The interface between the Oral and the Written. Cambridge University Press (1993)

23. Bachimont, B.: Ingénierie des connaisances et des contenus: Le numérique entre ontologies et documents. Lavoisier, Paris (2007)

24. Keraron, Y., Bachimont, B., Bernard, A.: Annotations to improve the using and the updating of Digital Technical Publications. In: Research in Engineering Design. Springer (2009)

25. Keraron, Y., Bachimont, B., Bernard, A.: Feedback from in-service use to improve digital information exchange between engineering and operators of complex systems. In: International Conference on Product Lifecycle Management, India, July 10-12 (2006) 